\title{
A EVASÃO ESCOLAR NUMA UNIVERSIDADE PÚBLICA, NO INTERIOR DO PARANÁ - ESTUDO DE CASO
}

\author{
Isabel Rodrigues Sanches ${ }^{1}$ \\ Simone Soares Nairne ${ }^{2}$
}

\begin{abstract}
Resumo: A evasão escolar é um problema educacional, pois é considerada como a perda de aluno. Essa perda gera graves consequências nas esferas sociais, econômicas e acadêmicas, causando sérios transtornos ao desenvolvimento do sujeito e, de maneira mais ampla, ao desenvolvimento da sociedade. 0 presente trabalho busca responder à questão que tem gerado angústias e inquietações nos profissionais envolvidos: por que os alunos abandonam os seus cursos? É uma pesquisa descritiva e analítica cujo desenvolvimento se deu a partir da análise de documentos e de inquérito por questionário aos alunos evadidos. Os dados obtidos com a pesquisa revelam que a causa "Reprovações Constantes" foi apontada por 41.5\% dos alunos respondentes ao questionário como determinante para a evasão. Os elementos evidenciados aqui indicam para a necessidade dos gestores criarem um sistema identificador do problema, que seja competitivo no intuito de manter estes alunos na Instituição, tendo em vista que grande parte dos evadidos continua a estudar em outras Instituições e os que estão fora do sistema, pretendem retomar os estudos.
\end{abstract}

Palavras-chave: Educação. Evasão escolar. Ensino superior. Brasil.

${ }^{1}$ Doutora em Educação. Universidade Lusófona (Portugal). E-mail: isabelrsanches@gmail.com

${ }^{2}$ Mestre em Ciências da Educação. Universidade Lusófona (Portugal). E-mail: sines6970@gmail.com 


\section{THE SCHOOL EVASION IN A PUBLIC UNIVERSITY IN THE INTERIOR OF PARANÁ - CASE STUDY}

Abstract: School dropout is an educational problem as it is considered as student loss. This loss generates serious consequences in the social, economic and academic spheres, causing serious disturbances to the development of the subject and, more broadly, to the development of society. The present work seeks to answer the question that has generated anxieties and worries in the professionals involved: why do students abandon their courses? It is a descriptive and analytical research whose development was based on the analysis of documents and a questionnaire survey of the evaded students. The data obtained with the research reveal that the cause "Constant Reprobation" was indicated by $41.5 \%$ of the subjects responding to the questionnaire as determinant for their evasion. The elements highlighted here indicate the need for managers to create a system that identifies the problem, which is competitive in order to keep these students in the Institution, since most of the evaded continues to study in other Institutions and those that are outside the system, intend to resume their studies.

Keywords: Education. School evasion. Higher education. Brazil.

\section{LA EVASIÓN ESCOLAR EN UNA UNIVERSIDAD PÚBLICA EN EL INTERIOR DE PARANÁ - ESTUDIO DE CASO}

Resumen: La deserción escolar es un problema educativo, ya que se considera la pérdida de estudiantes. Esta pérdida tiene graves consecuencias en la esfera social, económica y académica, causando graves perturbaciones en el desarrollo del tema y, en términos más generales, en el desarrollo de la sociedad. El presente trabajo busca responder a la cuestión que ha generado angustias e inquietudes en los profesionales involucrados: ¿por qué los alumnos abandonan sus cursos? Es una investigación descriptiva y analítica cuyo desarrollo se dio a partir del análisis de documentos y de encuesta por cuestionario a los alumnos evadidos. Los datos obtenidos con la investigación revelan que la causa "Reproches Constantes" fue señalada por el $41.5 \%$ de los sujetos respondedores al cuestionario como determinante para la evasión. Los elementos evidenciados aquí indican para la necesidad de los gestores crear un sistema identificador del problema, que sea competitivo con el fin de mantener a estos alumnos en la Institución, teniendo en vista que gran parte de los evadidos continúa estudiando en otras instituciones y los que están fuera del sistema, pretenden reanudar los estudios.

Palabras clave: Educación. Evasión escolar. Enseñanza superior. Brasil. 


\section{Introdução}

A evasão escolar é, indubitavelmente, uma questão que inquieta todos os envolvidos com a Educação. Para Camargo (2011, p. 61), “Superar a evasão e o fracasso escolar que exclui principalmente as classes desfavorecidas socialmente, deve ser meta principal do Estado e de todos os envolvidos com a Educação Pública brasileira".

Sabe-se que a Evasão Escolar é considerada como uma das deficiências mais preocupantes do sistema educacional do Brasil e esse tema não é recente. Questão longe de ser resolvida, vem sido discutida com muito afinco nos últimos tempos por investigadores e profissionais envolvidos na Educação. É um acontecimento que se encontra presente em todas as modalidades de ensino, portanto, também no Ensino Superior.

0 interesse pela temática que investiga o fenômeno da evasão escolar no ensino superior surgiu a partir da experiência do trabalho desenvolvido como Técnica Administrativa em Educação, lotada na Instituição objeto desse estudo, inaugurada em 2014, a qual abriu as portas com vagas para cinco cursos de graduação visando suprir as necessidades do mercado de trabalho regional e nacional.

Embora visível a grande expetativa dos estudantes em torno da implementação do novo Campus, foi possível verificar a ocorrência do fenômeno evasão ao longo dos anos. Em vista disso, com o intuito de ampliar o conhecimento sobre a questão e obter o maior número de informações no tocante à evasão escolar, a ideia do estudo volta-se para a investigação dos dados de todos os alunos que ingressaram nos cinco cursos de graduação nos anos de 2014 e 2015 e se evadiram até o final do ano de 2017.

É válido destacar que a escolha de pesquisar os alunos evadidos nos cinco cursos ofertados no Campus se deu porque o número de sujeitos para o ano de 2014 seria limitado. Sabe-se que quanto maior for o número de sujeitos, mais informação será obtida e mais consistente será o resultado, daí se ter optado por abranger também os alunos que ingressaram no ano de 2015 e se evadiram.

Para compreender o fenômeno da evasão escolar, procurámos responder à questão que tem gerado angústias e inquietações nos profissionais envolvidos: por que os alunos abandonam os seus cursos? 
Como Objetivo Geral, procuramos perceber as principais causas da evasão escolar em cinco cursos de graduação de uma Instituição Pública no interior do Paraná.

Como Objetivos Específicos procuramos caracterizar o perfil dos alunos evadidos; identificar o quantitativo de alunos evadidos dos cinco cursos de graduação que ingressaram nos anos de 2014 e 2015 e se evadiram até o final do ano de 2017; analisar as causas que levaram à evasão; identificar qual o curso da Instituição que é responsável pela maior taxa de evasão; analisar se os Planos Pedagógicos de cada curso favorecem a aprendizagem dos discentes e se configuram as pretensões e ansiedades da comunidade académica.

Considerando que toda Instituição tem sua própria organização e cultura, 0 fenômeno da evasão pode não acontecer da mesma maneira em todas as Instituições. Desse modo, um estudo sobre a evasão envolve analisar as diferentes situações que abarcam esse processo. Assim, a motivação por essa investigação justificou-se pela necessidade de se conhecer as causas da evasão, para que os responsáveis possam planear estratégias a fim de combater a evasão e, por fim, contribuir com a apresentação de soluções para diminuir o fenômeno na Instituição.

Caldas (2000) demonstra-se ciente da complexidade do problema da Evasão e o relaciona com outros temas importantes da Pedagogia, como as formas de avaliar, as reprovações constantes, os currículos e as disciplinas escolares. Afirma que para combater o problema é essencial atacá-lo em duas frentes: uma de ação imediata a fim de resgatar o aluno evadido e a segunda, de reestruturação interna que implica na discussão e avaliação de diversas questões referentes ao dia-a-dia escolar.

Para o pesquisador americano Rumberger (1995), a chave da compreensão e solução para o problema da evasão é encontrar as causas do problema. Ante esse fato, pode-se afirmar com veemência que conhecer o fenômeno e as causas da evasão no campus estudado, contribuirá para o desenvolvimento de estudos e estratégias que solucionem o problema existente. 


\section{Contextualização Teórica}

Educação - um direito de todos

A Educação escolar exerce um valioso papel na sociedade ao apresentar-se como elemento de inclusão e progresso de um país. Desse modo, a educação compreendida como processo pedagógico estruturado de intercessão no desenvolvimento na vida da sociedade é contemplado atualmente em investigações científicas que objetivam a fixação de políticas públicas estratégicas para o desenvolvimento das sociedades na sua totalidade. Contudo, o sistema educacional brasileiro ainda se depara com múltiplos caminhos desafiadores a percorrer, dentre os quais se evidencia a evasão escolar, principalmente no Ensino Superior. É notório que o processo educacional brasileiro tem passado por grandes transformações no decorrer dos tempos, com 0 objetivo de garantir o acesso e permanência de discentes nos bancos escolares e garantir-lhes êxito nesta jornada. Moran (2007, p. 79) afirma que "As mudanças que estão acontecendo são de tal magnitude que implicam reinventar a Educação, em todos os níveis, de todas as formas".

A Educação é um direito de todos. Esta é a premissa básica que se encontra alicerçada na Constituição Federal do Brasil (BRASIL, 1988) em seu artigo205. Assim, a Educação é um direito de todos e dever do Estado e da família, que será promovida e incentivada com a colaboração da sociedade, visando pleno desenvolvimento da pessoa, seu preparo para o exercício da cidadania e a sua qualificação para o trabalho. Estabeleceu ainda em seu artigo 206, inciso I, a igualdade de condições para o acesso e permanência na escola. Desta forma, a Educação deve ser promovida a favor do desenvolvimento da pessoa, exercício da cidadania e sua qualificação para o trabalho.

É permeada pela tríade escola, família e sociedade e, portanto, a Educação é um direito inalienável para todos os sujeitos de direitos, assim corrobora a Lei de Diretrizes e Bases da Educação Nacional - LDB (BRASIL, 1996).

Apesar de deveras transparente e óbvia no tocante à responsabilidade da família na orientação do percurso sócio educacional do educando, o que se constata é que nem todos os cidadãos são beneficiados pela Educação, quer seja em seu ingresso, 
como na conclusão de seus estudos. 0 que se observa, na realidade, é que a evasão se encontra cada vez mais presente na Educação.

É sabido que a escola é o espaço de aprendizagem e exercício da cidadania. Todos são iguais perante a Lei. Todos têm direito à Educação e é dever do Estado oferecer a Educação em todos os níveis. Para Serrão e Baleeiro (1999, p. 23),

A Educação é uma chave. Chave que abre a possibilidade de se transformar o homem anónimo, sem rosto, naquele que sabe que pode escolher, que é sujeito participante de sua reflexão, da reflexão do mundo e da sua própria história.

Embora os autores coloquem a Educação como uma forma de se atingir um fim, sabe-se que a realidade é muito diferente, pois muitos fatores vão além dos limites e esforços dos alunos. A Educação analisada sob o prisma jurídico nos remete à constatação de que existe um grande caminho a percorrer para se alcançarem os objetivos legais, já que, por um lado encontramos a lei conduzindo o educando à escola, ditando as regras e os direitos que os amparam. Por outro lado, a prática nos conduz à exclusão diante das desigualdades encontradas em todo o processo.

\section{Evasão Escolar}

Quando se menciona o tema evasão, a literatura exibe várias definições numa ampla base de dados, com autores divergindo entre si, muitas vezes sendo ambíguos e dificultando uma análise mais profunda do assunto. No pensamento de Amaral (2013, p. 30), "A questão que dificulta o estabelecimento de um consenso entre os autores quanto ao conceito de evasão discente diz respeito ao aspecto temporário ou definitivo da interrupção do vínculo estabelecido entre o estudante”.

Enquanto uns autores consideram que, para caracterizar a evasão, a interrupção do vínculo precisa ser definitiva, outros consideram que a interrupção temporária também caracteriza o fenômeno. Portanto, a compor esse panorama, a evasão escolar vem ocupando boa parte das discussões das autoridades ligadas à Educação, tratando-se de uma questão nacional.

Um conceito amplo e habitual nas investigações sobre o tema é o conceito apresentado pela Comissão Especial de Estudos sobre a evasão nas universidades públicas brasileiras (1996) que define a evasão como a saída definitiva do aluno de 
seu curso de origem, sem concluí-lo. No entendimento de Johan (2012, p. 65), a evasão é "Um fenômeno caracterizado pelo abandono do curso, rompendo com o vínculo jurídico estabelecido, não renovando o compromisso ou sua manifestação de continuar no estabelecimento de ensino”. Já Queiroz (2010) explica que a evasão escolar não é um enigma a ser resolvido apenas por algumas classes escolares, mas que se trata de um conteúdo de interesse nacional que vem ocupando importante papel nos debates e pesquisas educacionais no contexto do país. Destaca ainda o autor que se trata de um ponto inquietante para todos nele envolvidos, como os alunos, os pais, os professores, a instituição de ensino diretamente envolvida e a sociedade, já que pode ocasionar graves consequências, quer seja na esfera académica, social ou económica.

Para Boneti (2003, p. 35), “Os evadidos da escola são também os excluídos sociais [...]. A exclusão social resume-se na exclusão do direito à cidadania onde quer que ela se manifeste". Nesse contexto, a evasão escolar possui íntima ligação com a exclusão social, onde o sujeito que, deixando de ter acesso ao conhecimento se torna excluído de outros direitos. Assim sendo, toda a sociedade sofre e perde com a evasão do estudante.

A instituição de ensino que o abrigou também sofre com problemas de natureza pedagógica e administrativa já que gera perdas financeiras para si e para o governo, correspondente a gastos indevidos e investimentos desaproveitados com materiais e especialistas para vagas que são ocupadas por alunos que não concluem os cursos.

Segundo relatos de Arpini (2003) a instituição de ensino precisa construir um conhecimento no qual os sujeitos, que na vida têm mais dificuldades, sejam mais valorizados, pois quando um jovem é excluído do sistema educacional, ele se encontra, nesse momento, sendo incluído no espaço da marginalidade. Quando não vislumbram as possibilidades de futuro, agem como se não existissem expetativas de vida, sem projetos e objetivos, que the são tirados pela sociedade. Corroborando tal entendimento temos Moraes, Theóphilo e Lopes (2008) que afirmam que a evasão escolar é um dos maiores e mais preocupantes desafios do sistema educacional, pois é fator de desequilíbrio, desarmonia e desajustes dos objetivos educacionais pretendidos. Estes autores atribuem à escola a responsabilidade da evasão escolar, 
por não motivar os alunos e não atrair professores com melhores qualificações, oferecendo, assim, uma aprendizagem deficitária.

\section{Contextualização Metodológica}

Tipo de Pesquisa

Esta pesquisa buscou as técnicas necessárias para a realização de uma pesquisa qualitativa e quantitativa, utilizando a pesquisa documental e o inquérito por questionário.

A opção pela pesquisa qualitativa fundamenta-se na prerrogativa de podermos descrever e abordar, de forma minuciosa, a realidade em estudo e analisar os principais motivos que motivaram a evasão escolar. Minayo (1994, p. 6-7) preceitua que "a pesquisa qualitativa responde a questões muito particulares. Ela se preocupa, nas ciências sociais, com um nível de realidade que não pode ser quantificado". Quanto à utilização dos dois métodos juntos numa mesma pesquisa, Francisco (2010) refere que os métodos quantitativo e qualitativo não se excluem ou são opostos, mas complementam-se num processo de investigação pelas suas potencialidades e debilidades. A abordagem quanti-qualitativa é, segundo Polit e Hungler (1995, p. 277), "aquela que permite a complementação entre palavras e números, as duas linguagens fundamentais da comunicação humana”.

Porque o presente estudo recai numa Universidade do interior do Paraná, procurando perceber e aprofundar o que leva os estudantes desta universidade a abandonar a instituição, considera-se que se trata de um estudo de caso. Segundo Yin (2005) existem várias formas de se fazer uma pesquisa: estudo de caso, levantamentos, análises de informações e experimentos. Considera o Estudo de Caso apenas uma das maneiras de se realizar pesquisas nas ciências sociais, nas áreas direcionadas à prática e ainda para a pesquisa de teses e dissertações.

A abordagem descritiva do estudo remete-se à descrição das características de determinada população. Vergara (2009, p. 42), “expõe características de determinada população ou determinado fenômeno". No caso em tela, a apresentação do número de

alunos evadidos acompanhado das descrições das causas que o levaram ao fim, justifica a modalidade descritiva da pesquisa. A partir do interesse em conhecer a 
realidade dos alunos evadidos e explicar as características do fenômeno "evasão na Instituição" e justificar seus motivos, resta comprovado o caráter descritivo da pesquisa. A pesquisa documental do estudo se dá pela análise de documentos internos da instituição disponíveis na Secretaria Académica dos Cursos e suas Coordenações, responsáveis por arquivarem todos os dados acadêmicos dos alunos e documentos referentes aos cursos.

Técnica de pesquisa: inquérito por questionário

Atendendo ao fato de que o uso do inquérito por questionário é recomendado em estudos que possuam objetivos claros, suscetíveis de serem traduzidos em poucas e simples palavras, entendemos que se ajustava ao estudo. Dessa forma, optou-se pelo uso do inquérito por questionário com respostas de escolhas múltiplas, onde os alunos respondentes optaram por uma das alternativas, apresentadas de forma clara e objetiva. Os inquéritos por questionário foram encaminhados através do Google por ser totalmente gratuito, sendo utilizados para fins educativos, comerciais e não comerciais. 0 uso desse questionário facilitou construir, distribuir e gerenciar a pesquisa. Ofereceu praticidade e confiabilidade das respostas, auxiliando, inclusivamente, na elaboração dos gráficos dos resultados. Dos 174 indivíduos que ingressaram nos anos de 2014 e 2015 e se evadiram até o fim do ano de 2017, contamos apenas com 131 alunos evadidos disponíveis para a pesquisa, já que muitos não possuiam seu e-mail cadastrado. Richardson (1999, p. 157) afirma que:

Em geral, resulta impossível obter informações de todos os indivíduos ou elementos que formam parte do grupo que se deseja estudar; seja porque o número de elementos é demasiado grande, os custos são muito elevados ou ainda porque o tempo pode atuar como agente de distorção.

Constatou-se que foram recebidas 53 respostas dos entrevistados, resultando num índice de participação de retorno dos questionários de 40.45\%, a nossa amostra de pesquisa. Marconi e Lakatos (2005) afirmam que dos questionários que são enviados, em média, $25 \%$ retornam com respostas, percentagem ultrapassada no nosso caso. 


\section{Apresentação, Análise e Discussão dos Resultados}

Caraterização dos sujeitos evadidos

Gráfico 1 - Perfil dos alunos respondentes: Sexo

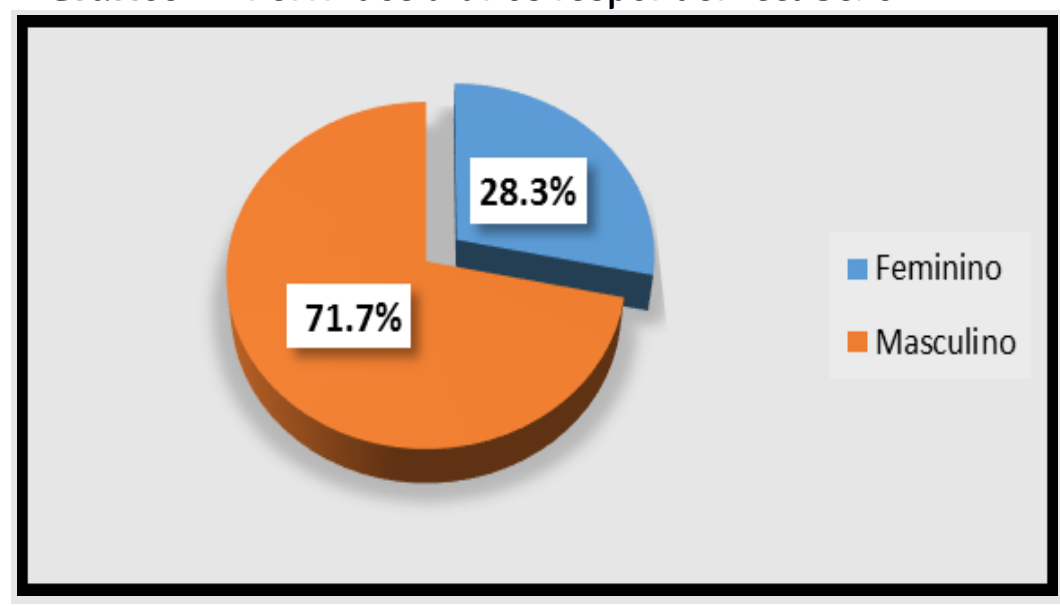

Fonte: As autoras.

Em relação ao sexo dos alunos evadidos, $\mathbf{7 1 . 7 \%}$ são do sexo masculino e $\mathbf{2 8 . 3} \%$ são do sexo feminino. 0 resultado da pesquisa contraria os estudos de Biazus (2004) e Hotza (2000), que apontam para um índice de evasão maior por parte de estudantes do sexo feminino.

Gráfico 2 - Perfil dos Respondentes: idade quando ingressou na Instituição

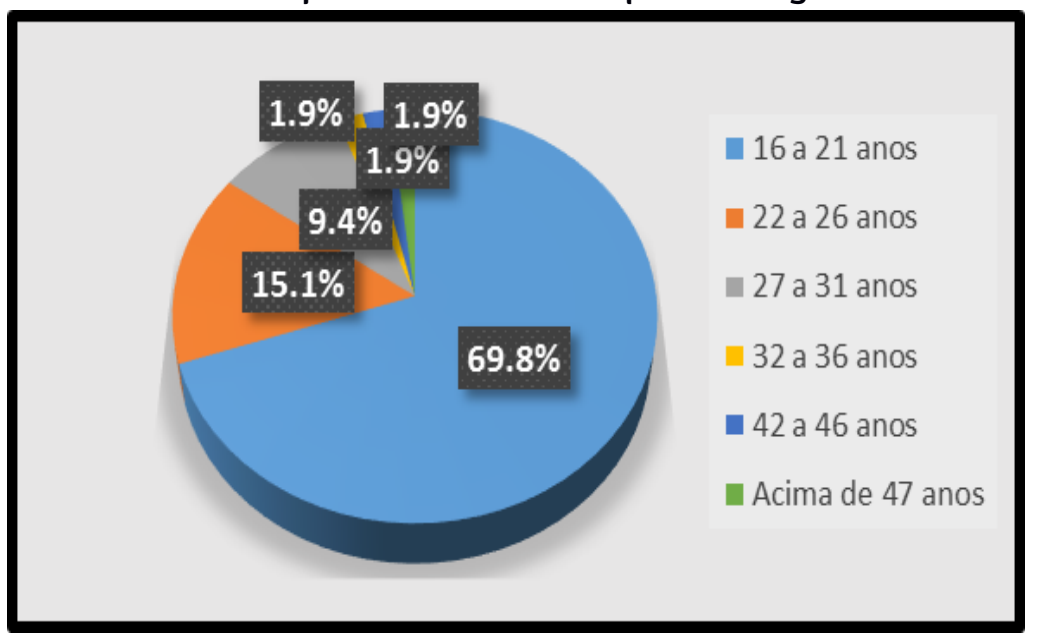

Fonte: As autoras.

A análise às idades dos sujeitos da pesquisa, no momento do ingresso na Universidade, indicou que a maior parte dos envolvidos, correspondente a $69.8 \%$ das 
respostas ao questionário, encontrava-se na faixa etária de 16 a 21 anos. Segundo estudos de Almeida (2008), os alunos compreendidos nesta faixa etária estão mais vulneráveis à evasão devido às diferenças do ambiente acadêmico e o ambiente egresso, ou seja, ambiente do Ensino Médio.

Gráfico 3 - Estado Civil no momento da Evasão

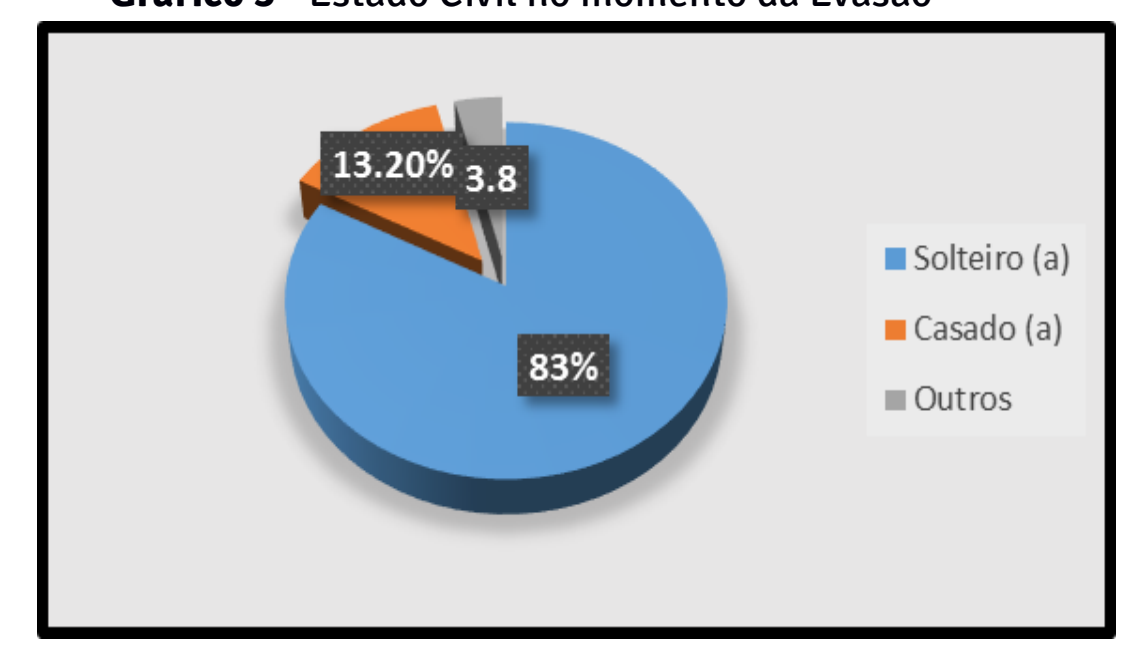

Fonte: As autoras.

No tocante ao estado civil dos alunos evadidos respondentes, pôde-se constatar que $83 \%$ eram solteiros no momento da evasão do curso, contrariando o mencionado por Gaioso (2005) que apresenta uma maior probabilidade de evasão nos indivíduos que são casados, tendo em vista terem de arcar com a mantença da família.

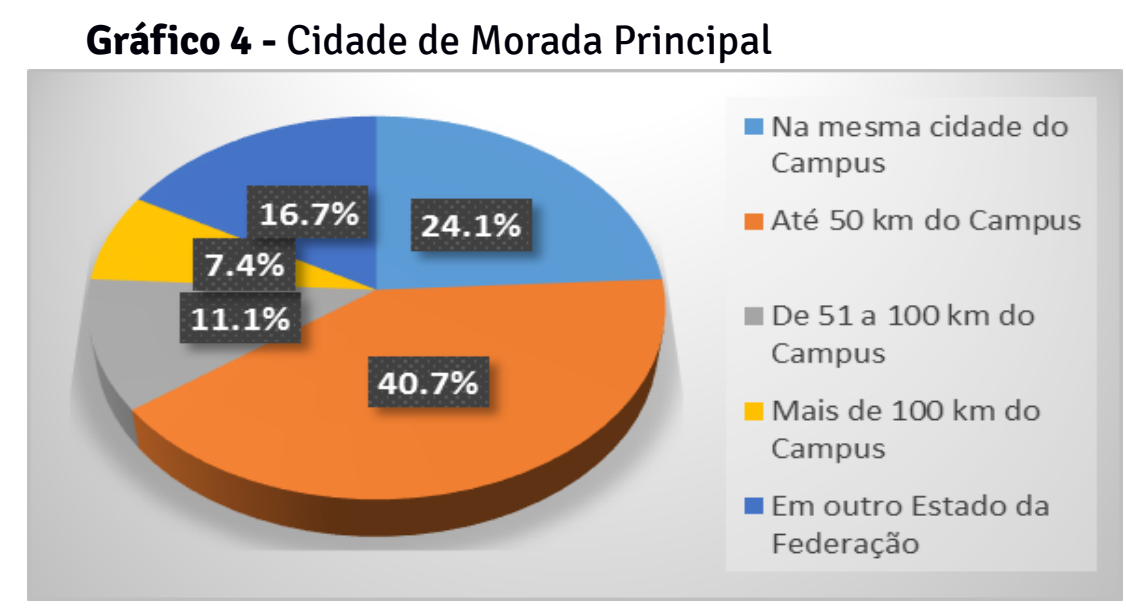

Fonte: As autoras.

Os dados revelam que $75.9 \%$ dos alunos evadidos têm a morada principal fora da cidade onde está localizado o Campus, o que pode ser considerado um fator indicativo para a Evasão. 
Gráfico 5 - Realização do Ensino Médio

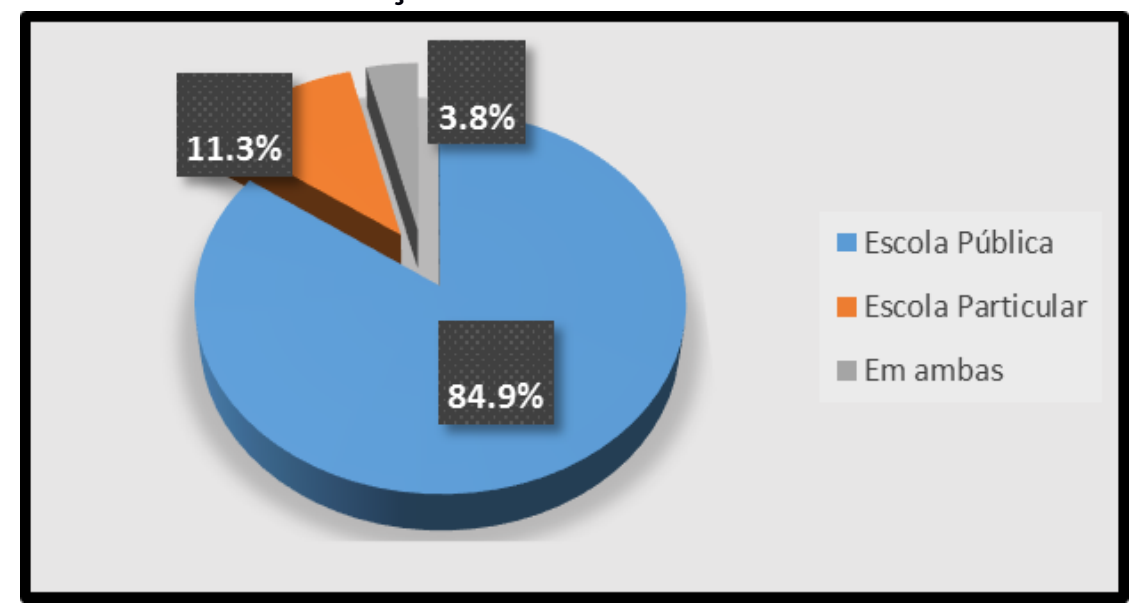

Fonte: As autoras.

Um total de $84.9 \%$ frequentou todo o Ensino Médio em escolas públicas, enquanto $11.3 \%$ frequentaram em escolas privadas. Os restantes $3.8 \%$ estudaram em ambas as escolas. É visível o desequilíbrio no que se refere ao tipo de escola, tendo em vista que o maior número de alunos evadidos frequentou o Ensino Médio em Escola Pública. Dos 53 respondentes, 67.9\% acusaram que sua forma de ingresso na Instituição se deu pelo ENEM e o restante, $32.1 \%$, via Vestibular, este, que antes era considerado a forma mais comum e acessível de ingresso numa Instituição Superior e está a ser gradualmente substituído pelo ENEM.

\section{Curso: escolha e permanência}

\section{Gráfico 6 - Motivos da Escolha do Curso}

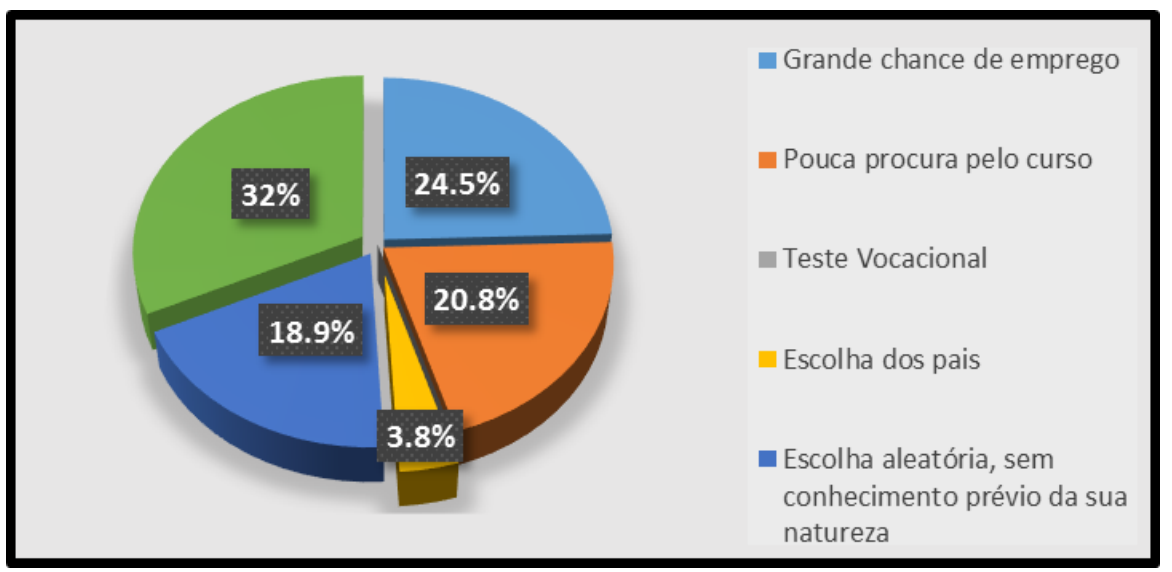

Fonte: As autoras. 
Para o tópico "Escolha do Curso", vemos que 24.5\% escolheram seu curso pela oportunidade que o mesmo oferecia de grande chance de emprego, mas $22.2 \%$ dos evadidos responderam que fizeram o teste vocacional, porém, nenhum deles respondeu que a escolha do curso se deu pelo resultado de Teste Vocacional.

Gráfico 7 - Expectativas quando ingressou no Curso

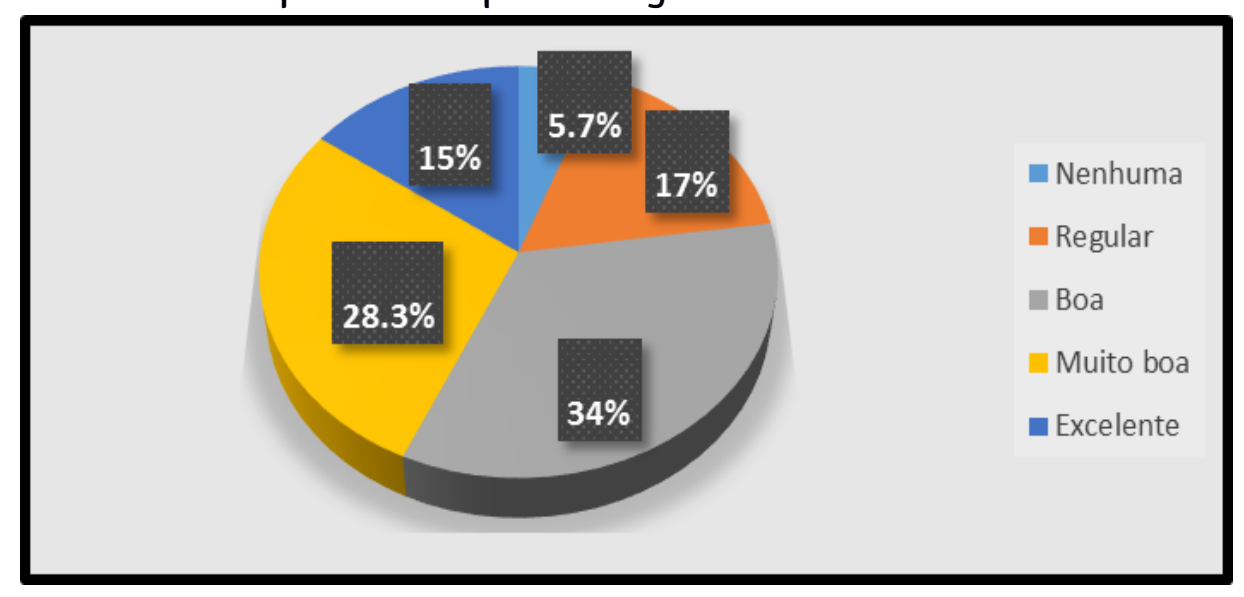

Fonte: As autoras.

0 gráfico demonstra que a maioria dos respondentes $(77.3 \%)$ possuía de boa a excelente expetativa do curso escolhido, no momento do ingresso. Constata-se que as boas expetativas não jogaram a favor da permanência no curso.

\section{Gráfico 8 - Tempo de frequência dos Participantes na Instituição}

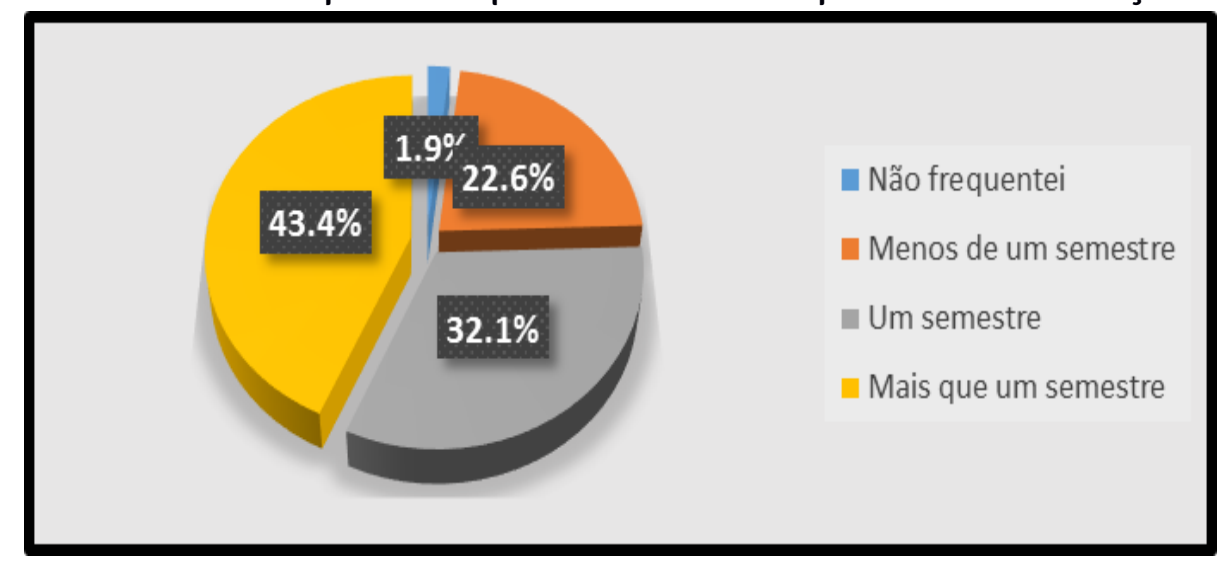

Fonte: As autoras.

Com relação ao tempo de frequência no curso, percebemos que $98.1 \%$ dos respondentes chegaram a iniciar o curso e apenas $1.9 \%$ não chegou a frequentar 0 curso em que fora aprovado. Contudo, dentre os alunos que chegaram a frequentar o 
curso, nota-se que o maior número de evasão se dá no início dos cursos (menos de um semestre e um semestre de frequência).

Sobre o Plano Pedagógico do Curso (PPC) do curso, perguntou-se aos evadidos se o conheceram. Em resposta, soube-se que $64.2 \%$ não chegou a conhecê-lo e o restante, $35.8 \%$ disse que sim, que conheceu o Plano Pedagógico de seu curso. Aos que responderam à alternativa afirmativa, foi proposta uma segunda questão que era saber se o PPC atendeu as expetativas do aluno. 55.6\% dos alunos responderam que o PPC atendeu as expetativas do aluno em relação ao curso escolhido.

Uma questão que se julgou extremamente importante a ser feita, para termos conhecimento se antes de evadirem houve uma comunicação dos seus motivos ao coordenador do curso ou a algum professor e tivemos como respostas: $18.9 \%$ responderam que sim e $81.1 \%$ responderam que não conversaram com o coordenador sobre a sua saída da Instituição.

Por fim, nas últimas questões percebemos que se tivessem a oportunidade, $37.7 \%$ voltariam ao curso, $35.1 \%$ não voltariam e $27.2 \%$ responderam que "talvez" voltariam. Dos 53 estudantes que responderam, $54.7 \%$ já se encontram a estudar em outra Instituição.

Ingressantes (2014 e 2015) e Evadidos (até 2017)

Apresenta-se, a seguir, o número de alunos que ingressaram nos anos de 2014 e 2015 e se evadiram até o final do ano de 2017 (Gráficos 12 e 13 respetivamente). Em seguida, far-se-á uma comparação desses dois gráficos (Gráfico 14) demonstrando, dessa forma, qual o curso que apresentou o maior número de evasão no período estudado. 
Gráfico 9 - Ingressantes (2014) e evadidos até 2017

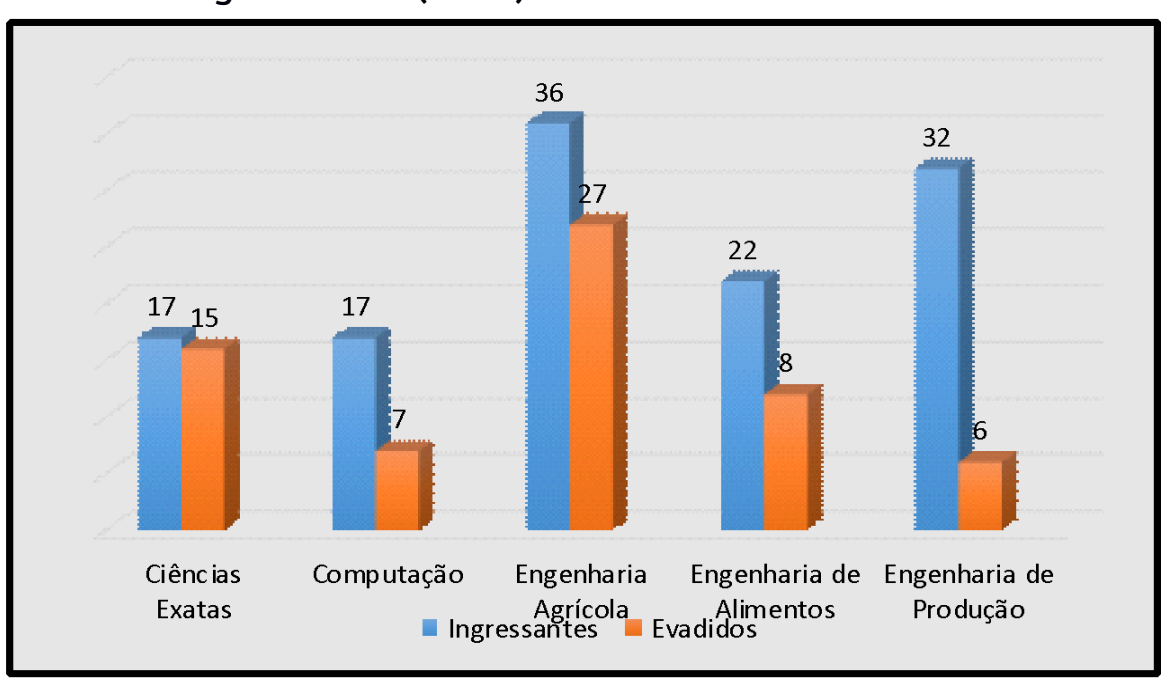

Fonte: As autoras.

De acordo com os documentos institucionais, a IES ambiente deste estudo, no ano de 2014 registou o total de 124 alunos ingressantes, contando com 63 alunos evadidos, ou seja, $50.80 \%$ dos ingressantes se evadiram até o final do ano de 2017.0 curso que mais contribuiu para a Evasão foi Ciências Exatas com um percentual de $88.23 \%$, seguido pelo curso de Engenharia Agrícola com um percentual de $75 \%$.

Gráfico 10 - Ingressantes (2015) e evadidos até 2017

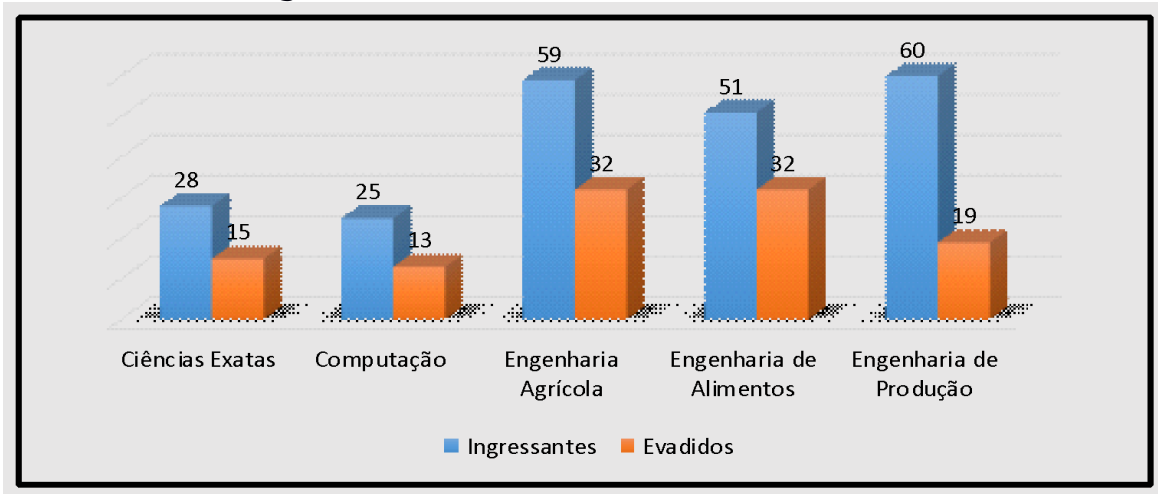

Fonte: As autoras.

Os documentos fornecidos pela Instituição estudada informam que no ano de 2015 o total de alunos ingressantes foi de 223, contando com 111 estudantes evadidos, ou seja, $49.77 \%$ dos ingressantes se evadiram até o final do ano de 2017.0 curso que mais contou com a Evasão foi Engenharia de Alimentos com um percentual de $62.74 \%$, seguido pelo curso de Engenharia Agrícola com um percentual de $54.23 \%$. Considerando os alunos que ingressaram nos anos de 2014 e 2015 temos um total de 
347 ingressantes. Destes, 174 se evadiram até o fim do ano de 2017 (63 alunos evadidos que ingressaram no ano de 2014 e 111 alunos evadidos que ingressaram no ano de 2015).

Ao proceder-se a uma comparação dos dados apresentados nos gráficos acima, tem-se:

Gráfico 11 - Comparativo da Evasão dos ingressantes em 2014 e 2015

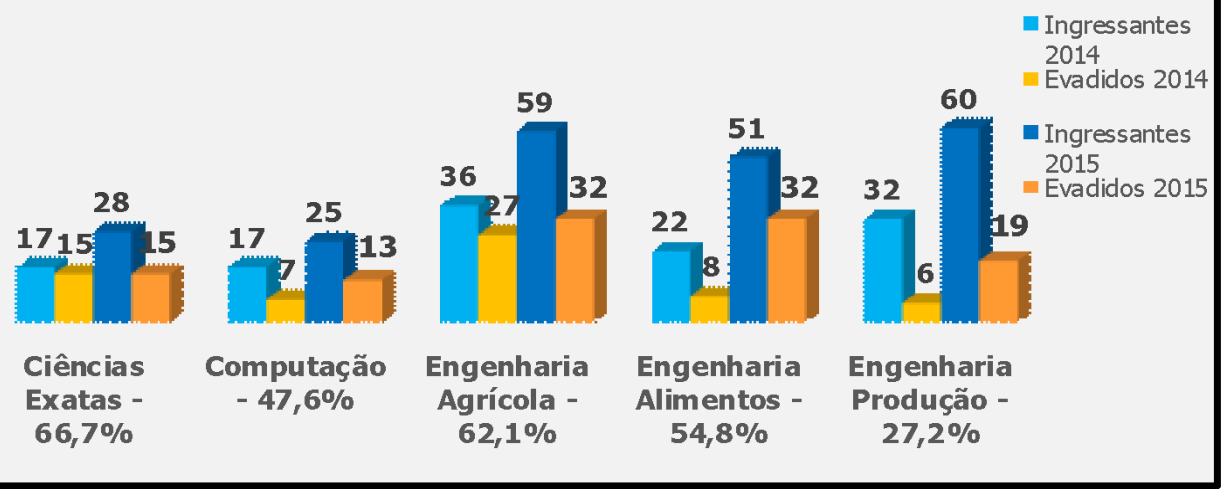

Fonte: As autoras.

Como se pode verificar no gráfico, o curso de Ciências Exatas foi o que apresentou o maior número de evasão nos ingressantes de 2014: foram 17 ingressantes e 15 evadidos, tendo este número de evadidos se repetido na turma de ingressantes de 2015. Já o curso de Engenharia de Alimentos apresentou o maior índice de evasão no ano de 2015, tendo 51 alunos ingressantes e destes, 32 evadidos.

0 curso de Ciências Exatas conta com o maior índice de evadidos (66.7\%), nos 2 anos, seguido pelo curso de Engenharia Agrícola (62.1\%).

Em todos os cursos aumentou o número de ingressantes, em 2015, verificando-se também o aumento do número de evadidos, excetuando o curso de Ciências Exatas que manteve 15 evadidos em cada um dos anos.

Evasão: motivos

Motivo 1 - Questões Familiares

Ao analisar os dados recebidos nos inquéritos, concluímos que $5.7 \%$ dos alunos responderam como sendo esse o fator de sua evasão.

Motivo 2 - Trabalho 
Ao conferir os dados recebidos, observa-se que para $17 \%$ dos respondentes, 0 trabalho contribuiu para a evasão. Constata-se que foi o segundo fator determinante da evasão, neste estudo.

\section{Motivo 3 - Reprovações Constantes}

Ao verificar os dados apresentados, verifica-se que esse motivo - Reprovações Constantes - foi apontado como determinante para a evasão por $41.5 \%$ dos sujeitos respondentes. Diante desses dados, considerou-se que esse fator influenciou de forma relevante a ocorrência do fenômeno da evasão estudada, por ser o que obteve maior frequência.

Quando se menciona a palavra "reprovação" leva o sujeito automaticamente ao pensamento “dificuldade de aprendizagem em disciplina específica”. Embora sejam termos que possam estar interligados, é importante mencionar que um termo pode surgir sem o outro. Correia (2008) nos sugere que devemos nos atentar que o termo “Dificuldades de Aprendizagem” tem sido utilizado em Portugal variando muito. Essas variações vão desde os problemas de aprendizagem do indivíduo (problemas intrínsecos) até aos problemas de aprendizagem referente ao ensino inadequado (origem extrínseca). Resta devidamente demonstrado que estudantes com repetências sucessivas ficam desmotivados e são os mais propensos a desistirem de seus cursos.

\section{Motivo 4 - Distância da casa dos pais ou onde mora/Cidade de Morada Principal}

Ao analisar os dados recebidos, verifica-se que $24.1 \%$ dos alunos respondentes moram na mesma cidade do Campus e que $51.8 \%$ residem fora do Município onde está implantado o Campus, a distância varia entre os 50 e $100 \mathrm{~km}$. Os restantes, que perfazem um total de $24.1 \%$, residem a mais de $100 \mathrm{~km}$ de distância, até mesmo em outro Estado da Federação. Nesses casos, percebe-se claramente o esforço para frequentar as aulas, o que torna um verdadeiro desafio, sobretudo quando, por algum motivo, os transportes não lhe são facultados.

A distância da casa dos pais ou onde mora/Cidade de Morada Principal ao Campus foi motivo da evasão para $3.8 \%$ dos alunos. 


\section{Motivo 5 - Desinteresse/falta de vontade/desmotivação}

Com o intuito de melhores condições de vida pessoal e profissional, o estudante ingressa no Ensino Superior dotado de imensa expetativa. Ocorre que somente estar matriculado no curso não leva o estudante ao término de seu curso. Ao apurar os dados apresentados, verifica-se que "Desinteresse/falta de vontade/desmotivação" foi apontado em $\mathbf{9 . 4 \%}$ das respostas dos alunos.

\section{Motivo 6 - Aulas/professores desestimulantes}

Os primeiros semestres de curso são essenciais para que o aluno crie um vínculo sólido com a Instituição e passe a interagir com os docentes e colegas. Para tal, é primordial que os professores, principalmente os dos períodos iniciais, desenvolvam práticas de ensino incentivadoras e significativas. 9.4\% dos alunos que responderam afirma que o motivo de sua saída da Instituição se deu por Aulas/professores desestimulantes.

Os motivos apontados pelos sujeitos desse estudo para a evasão da Instituição são os mais variados: reprovações constantes (10 lugar) falta de interesse, trabalho, professores/aulas desestimulantes, distância da morada principal e questões familiares, como mostra o Gráfico 12:

Gráfico 12 - Motivos da Evasão

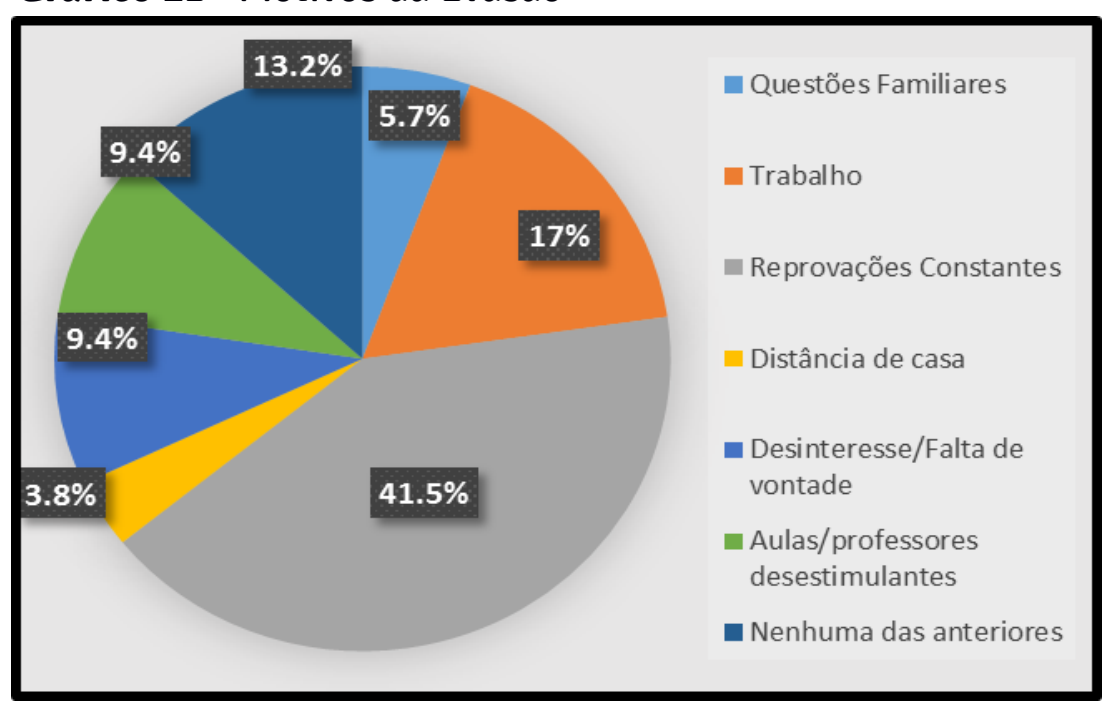

Fonte: As autoras. 


\section{Considerações Finais}

A pesquisa lançou a seguinte questão: por que os alunos abandonam os seus cursos? Para obter-se a resposta, a pesquisa foi conduzida no seu desenvolvimento pelos objetivos estabelecidos. De posse dos dados coletados através do questionário, foi possível delinear a caracterização do perfil dos alunos evadidos. Verifica-se que, em sua maioria, são do sexo masculino (71.7\%), com faixa etária entre 16 a 21 anos (69.8\%), solteiros (83\%) e residentes fora da cidade do Campus (75.9\%).

A maior parte realizou seus estudos em escola da rede pública de ensino (84.9\%) e ingressou na Instituição via ENEM (67.9\%).

Afirmaram que ao ingressarem na Instituição tinham uma boa expetativa do curso (34\%) e $43.4 \%$ afirmaram que o tempo máximo de frequência na Instituição foi de mais de um semestre.

Grande parte (64.2\%) alegou não conhecer o PPC e tampouco conversou com os professores (77.4\%) ou com o Coordenador do curso (81.1\%) sobre a sua decisão de saída da Instituição.

Apontam como fator determinante de sua saída as reprovações constantes (41.5\%). O motivo Trabalho foi apontado em seguida com um percentual de $17 \%$. Quando questionados se voltariam ao curso caso tivessem oportunidade, $37.7 \%$ disseram que sim e $27.2 \%$ responderam que talvez voltariam; $54.7 \%$ responderam que estão estudando em outra Instituição.

As dificuldades encontradas no primeiro ano do curso, citadas pelos alunos que responderam ao questionário, indicam basicamente as reprovações constantes e a dificuldade para conciliar trabalho e estudo.

Constata-se que o curso de Ciências Exatas conta com o maior índice de evadidos (66.7\%) seguido pelo curso de Engenharia Agrícola (62.1\%).

A análise dos Planos Pedagógicos dos Cursos (PPC) de cada curso da Instituição deu para se ter conhecimento que estão a favorecer a aprendizagem dos alunos e que configuram as pretensões e ansiedades da comunidade académica que os conhece.

Destarte, sabe-se que há muito que se evoluir no tocante ao tema evasão, quer seja a nível global ou mesmo local. Sabe-se também que as mudanças não se conquistam de um dia para o outro; além do mais, construir uma sociedade de direito 
é um trabalho difícil, que pode durar décadas, porque mudar o cenário social exige mudanças de comportamentos com ordenação. Para alcançar essas mudanças são precisos anos e é preciso também que se haja vontade e que acreditem que podemos chegar lá.

\section{Referências}

ALMEIDA, O. Evasão em cursos a distância: análise dos motivos de desistência. Brasília: Universidade de Brasília, 2008. Disponível em: http://www.abed.org.br/congresso2008/tc/552008112738PM.pdf. Acesso em: 10 out. 2018.

AMARAL, J. B. Evasão discente no ensino superior: um estudo de caso no instituto federal de educação, ciência e tecnologia do ceará. 2013. Dissertação (Mestrado) Universidade Federal do Ceará, Sobral, 2013. Disponível em: http://www.repositorio.ufc.br/bitstream/riufc/8013/1/2013_dis_jbamaral.pdf. Acesso em: 10 out. 2018.

ARPINI, D. Violência e exclusão: adolescência em grupos populares. Bauru: EDUSC, 2003.

BIAZUS, C. Sistema de fatores que influenciam o aluno a evadir-se dos cursos de graduação na UFSM e na UFSC: um estudo de caso de Ciências Contábeis. 2004. Tese (Doutorado) - Universidade Federal de Santa Catarina, Florianópolis, 2004.

BONETI, L. Educação, exclusão e cidadania. ljuí: Unijuí, 2003.

BRASIL. [Constituição (1988)]. Cosntituição da República Federativa do Brasil. Brasília: Presidência da República, 1988.

BRASIL. Lei $n^{\circ}$ 9.394, de 20 de Dezembro de 1996. Estabelece as diretrizes e bases da educação nacional. Brasília: Presidência da República, 1996. Disponível em: www.planalto.gov.br/ccivil_03/leis/L9394.htm. Acesso em: 11 nov. 2018

\section{COMISSÃO ESPECIAL DE ESTUDOS SOBRE A EVASÃO NAS UNIVERSIDADES} PÚBLICAS BRASILEIRAS. Diplomação, retenção e evasão nos cursos de graduação em instituições de ensino superior públicas. [Brasília]: ANDIFES: ABRUEM: SESU: MEC, 1996.

CALDAS, E. Combatendo a evasão escolar. São Paulo: Instituto Polis, 2000.

CAMARGO, D. Evasão escolar na primeira série do ensino médio: desafios e superações. 2011. Dissertação (Mestrado) - Universidade do Oeste de Santa Catarina, Santa Catarina, 2011.

CORREIA, L. Dificuldades de aprendizagem específicas: contributos para uma definição portuguesa. Porto: Porto Editora, 2008. 
FRANCISCO, M. A recolha de dados. Metodologias de investigação na educação, [Portugal], 2010. Disponível em: https://miemf.wordpress.com/act2/. Acesso em: 10 maio 2017.

GAIOSO, N. P. O fenômeno da evasão escolar na educação superior no Brasil. Dissertação de Mestrado em Educação. Brasília: Universidade Católica de Brasília, 2005.

HOTZA, M. A. O abandono nos cursos de graduação da UFSC em 1997: a percepção dos alunos-abandono. 2000. Dissertação (Mestrado) - Universidade Federal de Santa Catarina, Florianópolis, 2000. Disponível em: https://repositorio.ufsc.br/handle/123456789/79172. Acesso em: 10 maio 2017.

JOHAN, C. Evasão escolar no Instituto Federal Sul-Rio-Grandense: um estudo de caso no campus Passo Fundo. 2012. Dissertação (Mestrado em Educação) - Universidade de Passo Fundo, Passo Fundo, 2012. Disponível em:

http://tede.upf.br/jspui/bitstream/tede/739/1/2012Cristiane_Cabral_Johann.pdf. Acesso em: 10 maio 2017.

MARCONI, M.; LAKATOS, E. Fundamentos de metodologia científica. São Paulo: Atlas, 2005.

MINAYO, M. C. Ciência, técnica e arte: o desafio da pesquisa social. Petrópolis: Vozes, 1994.

MORAES, E.; THEÓPHILO, C.; LOPES, M. A. Evasão no ensino superior: estudo dos fatores causadores da evasão no curso de Ciências Contábeis da Universidade Estadual de Montes Claros. Montes Claros: Unimontes, 2008. Disponível em https://congressousp.fipecafi.org/anais/artigos102010/419.pdf. Acesso em: 11 maio 2017.

MORAN, J. M. A educação que desejamos. Campinas: Papirus, 2007.

POLIT, D.; HUNGLER, B. Fundamentos de pesquisa em enfermagem. Porto Alegre: Artes Médicas, 1995.

QUEIROZ, L. Um estudo sobre a evasão escolar: para se pensar na inclusão escolar. Cuiabá: UFMT, 2010.

RICHARDSON, R. Pesquisa social: métodos e técnicas. São Paulo: Atlas, 1999.

RUMBERGER, R. Dropping out of middle school: a multilevel analysis of students and schools. American Educational Research Journal, Washington, v. 32, n. 4, p. 583-625, 1995.

SERRÃO, M.; BALEEIRO, M. C. Aprendendo a ser e a conviver. 2. ed. São Paulo: FTD, 1999.

VERGARA, S. Projetos e relatórios de pesquisa em administração. São Paulo: Atlas, 2009.

YIN, R. Estudo de caso: planejamento e métodos. Porto Alegre: Bookman, 2005. 
Recebido em: 03/05/2019

Aceito em: 19/12/2019 